\title{
Copper Oxide Nanoparticles Toxicity on Eisenia fetida Earthworms and Bacterial Species
}

\author{
K.V. Pavani ${ }^{1}$, K. Gayathramma², Priyanka Aduri ${ }^{3, *}$ \\ ${ }^{1}$ Department of Biotechnology, Gokaraju Rangaraju Institute of Engineering and Technology, Bachupally, Hyderabad - 500 090, Telangana, India. \\ ${ }^{2}$ Department of Botany, MES Degree College of Arts, Commerce and Science, Malleswaram, Bangalore - 560 003, Karnataka, India. \\ ${ }^{3}$ Department of Biotechnology, Chaitanya bharathi institute of Technology, Gandipet, Hyderabad - 500075, Telangana, India.
}

\section{ARTICLE DETAILS}

\section{Article history:}

Received 29 March 2018

Accepted 13 April 2018

Available online 21 June 2018

\section{Keywords:}

Copper Oxide Nanoparticles

Anti-Microbial Activity

Earthworms

\begin{abstract}
A B S T R A C T
The extensive use of nanoparticles (NPs) in a variety of applications has raised great concerns about their environmental fate and biological effects. To investigate the role of CuO NPs in soil on microbes and earthworms, we exposed microorganisms and earthworms (Eisenia fetida) to different concentrations of $\mathrm{CuO}$ NPs $<100 \mathrm{~nm}$. The results obtained showed that the CuO NPs exhibited good antimicrobial activity. A dose-related increase in mortality was not observed in earthworms exposed to $\mathrm{CuO}$ NPs by soil contact method. In direct contact method the average death time of E. fetida to CuO NPs is not dose related. Dose related weight loss of earthworms was noticed after 15 days of exposure. This study will be very useful in regulation of nanomaterials that are entering into the environment.
\end{abstract}

\section{Introduction}

Manufactured nanoparticles have unique properties and a wide range of applications [1]. Metal oxide nanoparticles introduction into soil as well as the aquatic environment received considerable attention. Now a day's research was focused on the impact of nanoparticles on terrestrial organisms $[2,3]$. Nanoparticles are so tiny that small quantities could have major toxic effects, because of their large surface [4]. Copper oxide $\mathrm{CuO}$ NPs are one of the most important nano metals which are commercially produced and are used in various industries. CuO NPs have been used as anode materials of the lithium ion batteries due to their good electrochemical properties, high rate of effectiveness, low cost, and recyclability [5]. It can also be used as an additive in oil, plastic and metallic coating $[6,7]$.

Earthworms are the most abundant invertebrates in the soils of temperate regions and are extremely important for soil formation [8]. Earthworms participate in nutrient cycling and in the formation of the soil from the physical, chemical and microbial perspectives [9]. They improve the soil structure by increasing the porosity, which affects aeration, water dynamics and organic and inorganic matter breakdown $[10,11]$. Earthworms are permanently in close contact with soil particles and microorganisms present in the soil via both skin and an alimentary tract $[12,13]$. Therefore, they are significantly affected by the pollutants that reach the soil system and are thus well suited for the monitoring of soil contamination. The presence of contaminants in the soil disturbs major physiological functions of earthworms, such as survival, nutrition, immunity, growth, and reproduction, and these effects depend on the matrix, exposure time, and the pollutants in the environment. This study helps in ecological risk assessment of $\mathrm{CuO}$ NPs on earthworms and bacteria in soil.

\section{Experimental Methods}

2.1 Test Compound

$\mathrm{CuO}$ nanoparticles ( $<100 \mathrm{~nm}$ particle size) were purchased from SigmaAldrich (Germany).

\subsection{Test Organisms}

Adult earthworms E. fetida were obtained from a local worm post dealer (Hyderabad). All earthworms were maintained in the laboratory at 16-17 ${ }^{\circ} \mathrm{C}$ and 12:12 light/darkness regime. Dairy manure which was dried at 100 ${ }^{\circ} \mathrm{C}$ was powdered and added as food, twice a week. Groups of animals (10 individuals per $0.2 \mathrm{~kg}$ soil samples per each group) were maintained in plastic boxes covered with perforated lids.

\subsection{Method of Exposure}

\subsubsection{Exposure by Direct Contact Method}

Adult Eisenia fetida were rinsed in distilled water and kept in a tray with distilled water for 2 hours to purge their gut contents. The earthworms were again rinsed in distilled water and placed in vials. One earth worm was placed in each vial. Exposure concentrations of CuO NPs were 100, $150,200,250$ and $300 \mathrm{mg} / \mathrm{mL}$. Control vials were treated with $1 \mathrm{~mL}$ of distilled water. Earthworms were considered as dead when they failed to respond to a gentle mechanical stimulus to their front end. Acute toxicity was evaluated by earthworm mortality.

\subsubsection{Exposure by Soil Contact Method}

Effect of CuO NPs on earthworm's mortality was studied using soil exposed to $\mathrm{CuO}$ NPs. For each treatment, three plastic boxes were used, each housing ten earthworms. The lid of the box contains air holes for gaseous exchange. $20 \mathrm{~mL}$ each of different concentrations of CuO NPs (100, $150,200,250$ and $300 \mathrm{mg} / \mathrm{mL}$ ) were sprayed on the $200 \mathrm{~g}$ of soil present in each box. In control box water was sprayed. The CuO NPs was sprayed on alternate days to the feed. The numbers of earthworms in the boxes were counted every day. Earthworms were washed with water to remove the adhering substrates and were placed in trays for 2 hours therefore, stomach contents were emptied into a tray from their bodies and dried with tissue paper and weighed after 15 days.

\subsection{Antibacterial Activity of CuO NPs by Well Diffusion Assay}

Antimicrobial activity of CuO NPs was determined using GRAMnegative and Gram-positive bacteria (Bacillus subtilis, Pseudomonas aeruginosa and E. coli) by well diffusion method. Nutrient agar and LB plates were prepared and the wells were punched into the agar with the sterile gel puncher. $0.5 \mathrm{~mL}$ of the inoculum was placed onto the surface of the nutrient plates and allowed to remain in contact for $10 \mathrm{~min}$. The wells in each plate were loaded with $10 \mu \mathrm{L}$ of different concentrations i.e. 10, 20, 30,40 and $50 \mathrm{mg} / \mathrm{mL}$ of $\mathrm{CuO}$ nanoparticles. Sterile D/W was used as 
control. After keeping the plates at room temperature for 1 hour. So that nanoparticles diffuse across the surface, the plates were incubated at 37 ${ }^{\circ} \mathrm{C}$ for 24 hours.

\section{Results and Discussion}

The production, use, and disposal of nanomaterials will inevitably lead to their release into air, water and soil [14]. In this study, we focused on toxicological effects of $\mathrm{CuO}$ NPs. To exclude the interactions $\mathrm{CuO}$ NPs with soil constituents in order to focus only on the effects of selected toxicants, the earth worms were exposed directly to aqueous medium containing CuO NPs. One of the primary problems in toxicity studies with NPs is the preparation of the exposure medium, because the particles tend to form aggregates in water. The results indicated that the average death time of E. fetida to CuO NPs is not dose related (Fig. 1). This supports the importance of dissolution of $\mathrm{CuO}$ NPs in water as a critical factor to understand the mortality of earthworms. Also Borm et al. [15] reported that the adsorption/desorption and agglomeration reactions, dissolution is likely to be an important determinant of fate and persistence of CuO NPs.

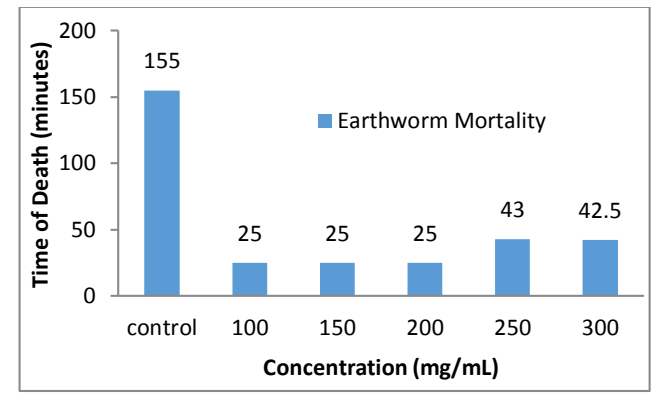

Fig. 1 Exposure of E. fetida to CuO NPs solution

Earthworms actively influence chemical and physical properties of soil affecting mobility, bioavailability and entrance to food chain, transport, and toxicity of the metals. Earthworm was washed, dried with tissue paper and weighed after 15 days. Earth worms survived at higher concentrations of CuO NPs. There was loss of weight of worms at higher concentrations (Fig. 2). Mwaanga revealed that there was loss of weight of earthworms that was dose related [16]. Some other workers noticed that aggregation of nanoparticles at higher concentrations may be the reason for the survival of earthworms [17]. Behboudi et al. reported that the ZnO NPs absorption and accumulation in Eisenia fetida tissues enhanced with increasing nanoparticles concentrations, after seven and fourteen days and weight gain decreased by increasing nanoparticles concentrations after seven days [18].

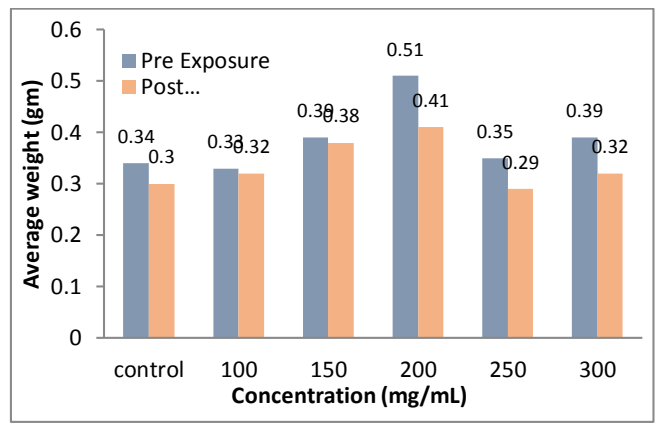

Fig. 2 Weight of E. fetida exposed to CuO NPs in soil

Table 1 Death of earthworms exposed to CuO NPs in soil

\begin{tabular}{llll}
\hline S. No & $\begin{array}{l}\text { Concentration of } \\
\text { CuO NPs }\end{array}$ & $\begin{array}{l}\text { Number of days of } \\
\text { Exposure }\end{array}$ & Number of Deaths \\
\hline 1 & $100 \mathrm{mg} / \mathrm{mL}$ & $9^{\text {th }}$ day & 1 \\
& & $11^{\text {th }}$ day & 1 \\
& & $15^{\text {th }}$ day & 1 \\
2 & \multirow{2}{*}{$150 \mathrm{mg} / \mathrm{mL}$} & $4^{\text {th }}$ day & 2 \\
& & $1^{\text {th }}$ day & 1 \\
3 & $200 \mathrm{mg} / \mathrm{mL}$ & $8^{\text {th }}$ day & 1 \\
& & $11^{\text {th }}$ day & 1 \\
& & $15^{\text {th }}$ day & 1 \\
4 & \multirow{2}{*}{$250 \mathrm{mg} / \mathrm{mL}$} & $6^{\text {th }}$ day & 2 \\
& & $13^{\text {th }}$ day & 1 \\
5 & $300 \mathrm{mg} / \mathrm{mL}$ & $4^{\text {th }}$ day & 1 \\
& & $5^{\text {th }}$ day & 2 \\
\hline
\end{tabular}

The study of the toxicity effects of CuO NPs on the Eisenia fetida earthworm showed that the number of deaths is not dose related but the effect on the earthworm is dosing related (Table 1). At higher concentrations, death of the earthworm occurred on $5^{\text {th }}$ day, whereas at low concentrations on $15^{\text {th }}$ day. Studies carried out by Chang et al. on toxicity effects of ZnO NPs and CuO NPs on earthworms have indicated no mortality. Mortality of earthworms depends on passage of NPs through plasma membrane via ion-gated channels and transporter proteins [19], also depends on soil organic matter, ingestion of feed and soil contaminated with NPs and bioaccumulation.

\subsection{Anti-Bacterial Activity of CuO NPs}

As the concentration of $\mathrm{CuO}$ NPs is increased the zone of inhibition is also increased (Fig. 3). $10 \mathrm{mg} / \mathrm{mL}$ of $\mathrm{CuO} \mathrm{NPs}$ is more effective on Pseudomonas aeruginosa than Bacillus subtilis and E. Coli. This suggest that the higher concentration of CuO NPs most effectively inhibits the growth of Pseudomonas aeruginosa, Bacillus subtilis and E .coli. Rachel Rutecki et al. reported that high concentration of nano $\mathrm{CuO}$ is required to achieve a bactericidal effect [20]. It was also reported that $\mathrm{CuO}$ nanoparticles inhibit the growth of E. coli, Pseudomonas aeruginosa, and S. aureus in a time and dose dependent manner [21]. Baek et al. showed that, Escherichia coli is highly susceptible, whereas Staphylococcus aureus and Bacillus subtilis are less susceptible to $\mathrm{CuO}$ NPs [22]. CuO NPs showed a major antimicrobial activity against Bacillus subtilis [23] .The disparity in results between similar tests could arise from differences in test organisms, experimental methods, method of preparation of nanoparticles and agglomeration effect $[24,25]$

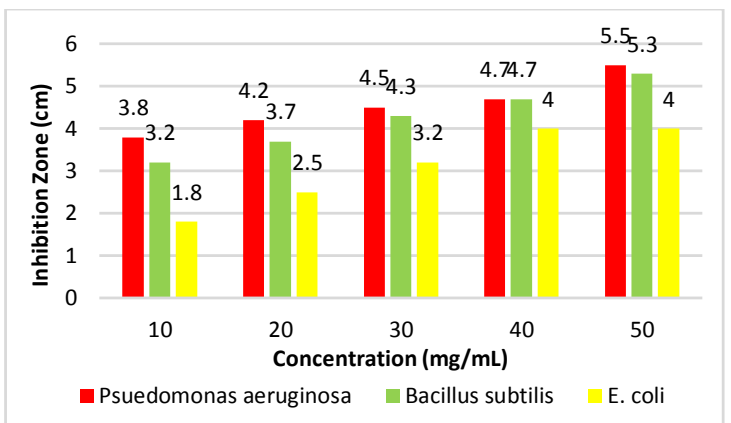

Fig. 3 Antibacterial activity of CuO NPs

\section{Conclusion}

$\mathrm{CuO}$ NPs has shown the ability to cause toxic effect on earth worms in soil. There was a significant relationship between NPs concentrations and weight of the earth worms. Our study revealed that at higher concentration death of earth worms occurs on the $5^{\text {th }}$ day of exposure. Nano $\mathrm{CuO}$ exhibited best anti-bacterial properties against 3 tested bacteria. This study will be very useful in ecological risk assessment and regulation of $\mathrm{CuO}$ NPs used in various fields.

\section{References}

[1] A. Nel, T. Xia, L. Madler, N. Li, Toxic potential of materials at the nanolevel, Science 311 (2006) 622-627.

[2] C.W. Hu , M. Li, Y.B. Cui, D.S. Li, J. Chen, L.Y. Yang, Toxicological effects of $\mathrm{TiO}_{2}$ and $\mathrm{ZnO}$ nanoparticles in soil on earthworm Eisenia fetida, Soil Biol. Biochem. 42 (2010) 586-591.

[3] E. Lapied, E. Moudilou, J.M. Exbrayat, H. Oughton, E.J. Joner, Silver nanoparticle exposure causes apoptotic response in the earthworm Lumbricus terrestris (Oligochaeta), Nanomed. 5 (2010) 975-984.

[4] Sachindri Rana, P.T. Kalaichelvan, Ecotoxicity of nanoparticles, ISRN Toxicology 2013 (2013) 574648-1-11.

[5] H. Wang, Q. Pan, J. Zhao, W. Chen, Fabricationn of CuO/C films with sisal- like hierarchical microstructures and its application in lithium ion atteries, J. Alloys Compd. 476 (2009) 408-413.

[6] C. Bouvy, W. Marine, S.B.L. Sporken, Colloids and surfaces, Physicochem. Eng. Asp. 300 (1-2) (2007) 145-149.

[7] D. Lin B. Xing, Phytotoxicity of nanoparticles, inhibition of seed germination and root growth, Environ. Pollut. 150(2) (2007) 243-250.

[8] C.A. Edwards, Earthworm Ecology. CRC Press, Boca Raton, FL. 2004.

[9] M.D. Bartlett, M.J.I. Briones, R. Neilson, O. Schmidt, D. Spurgeon, R.E. Creamer, A critical review of current methods in earthworm ecology from individuals to populations, Eur. J. Soil Biol. 46 (2010) 67-73.

[10] B. Wen, Y. Liu, X.Y. Hu, X.Q. Shan, Effect of earthworms (Eisenia fetida) on the fractionation and bioavailability of rare earth elements in nine Chinese soils, Chemosphere 63 (2006) 1179-1186. 
[11] E. Ruiz, J. Alonso-Azcarate, L. Rodriguez, Lumbricus terrestris L. activity increases the availability of metals and their accumulation in maize and barley, Environ. Pollut. 159 (2011) 722-728.

[12] T. Jager, H.L.J. Roel Fleuren, W. Roelofs, C. Arthur de Groot, Feeding activity of the earthworm Eisenia andrei in artificial soil, Soil Biol. Biochem. 35 (2003) 313-322.

[13] H.L Drake, M.A. Horn, As the worm turns: the earthworm gut as a transient habitat for soil microbial biomes, Ann. Rev. Microbiol. 61 (2007) 169-189.

[14] D.H. Lin, B.S. Xing, Phytotoxicity of nanoparticles, inhibition of seed germination and root growth, Environ. Pollut.150 (2007) 243-250.

[15] P. Borm, F.C. Klassig, T.D. Landry, B. Moudgil, J. Pauluhn, K. Thomas, R. Trottier, S. Wood, Research strategies for safety evaluation of nanomaterials, Part V, Role of dissolution in biological fate and effects of nanoscale particles, Toxicol. Sci. 90 (2006) 23-32.

[16] P. Mwaanga, S. Mbulwe, P. Shumbula, J. Nyirenda, Investigating the toxicity of $\mathrm{cu}, \mathrm{CuO}$ and $\mathrm{ZnO}$ nanoparticles on earthworms in urban soils, J. Pollut. Eff. Cont. 5(3) (2017) 1-9.

[17] S. Gupta, T. Kushwah, S. Yadav, Toxicity of ZnO nanoparticles on earthworm Eisenia fetida (Savigny, 1826) (Oligochaeta) and its potential as biotransforming agent, Advances in Earthworm Taxonomy VI (Annelida: Oligochaeta). - Proceedings of the 6th International Oligochaete Taxonomy Meeting (6th IOTM), Palmeira de Faro, Portugal, 2013.
[18] F. Behboudi, Alahdadi, M. Goltapeh, Malakootikhah, S. Hosseinifard, Investigation of effects of $\mathrm{ZnO}$ nanoparticles on survival, reproduction, absorption, weight gain and accumulation in Eisenia foetida earthworm tissues in two different substrates, Int. J. Agron. Plant Prod. 1(3) (2010) 98-104.

[19] Y. Chang, M. Zhang, L. Xia, J. Zhang, G. Xing, The toxic effects and mechanisms of $\mathrm{CuO}$ and ZnO nanoparticles, Mater. 5 (2012) 2850-2871.

[20] R. Rutecki, Effect of copper nanoparticles on microbes, Lett. Gen. Microbiol. 1 (2013) 28-30.

[21] G. Ungur, J. Hruza, Influence of copper oxide on the formation of polyurethane nanofibers via electrospinning, Fibers Polym. 16 (2015) 621-628.

[22] Y.W. Baek, Y.J. An, Microbial toxicity of metal oxide nanoparticles (CuO, NiO, $\mathrm{ZnO}$, and $\mathrm{Sb}_{2} \mathrm{O}_{3}$ ) to Escherichia coli, Bacillus subtilis, and Streptococcus aureus, Sci. Tot. Environ. 409 (2011) 1603-1608.

[23] D. Das, B.C. Nath, P. Phukon, S.K. Dolui, Synthesis and evaluation of antioxidant and antibacterial behavior of CuO Nanoparticles, Colloids Surf. B. Biointerf. 101 (2013) 430-433.

[24] K. Tiede, M. Hassellov, E. Breitbarth, Q. Chaudhoury, A. Boxall, Considerations for environmental fate and ecotoxicity testing to support environmental risk assessments for engineered Nanoparticles, J. Chromatogr. A 1216 (2009) $503-$ 509.

[25] D.R. Boverhof, R.M. David, Nanomaterial characterization, considerations and needs for hazard assessment and safety evaluation, Anal. Bioanal. Chem. 396 (2010) 953-961. 